\title{
Composição centesimal do fruto, extrato concentrado e da farinha da uva-do-japão
}

\author{
Chemical composition of fruit, concentrated extract and flour from "Japanese grape"
}

\author{
Marlene Bampi ${ }^{I}$ Milene Oliveira Pereira Bicudo ${ }^{I}$ Paulo Sérgio Growoski Fontoura ${ }^{\text {II }}$ \\ Rosemary Hoffman Ribani ${ }^{{ }^{*}}$
}

\section{RESUMO}

\begin{abstract}
A Hovenia dulcis, mais conhecida como uva-dojapão, pertence à família Rhamnaceae, é natural da China, Japão e Coréia, sendo largamente difundida no sul do Brasil. Rica em açúcares e bem aceita para consumo humano, pode ser consumida in natura ou processada. Não há na literatura relatos de seu aproveitamento em produtos alimentícios. $O$ presente trabalho teve por objetivo determinar a composição centesimal do fruto, do extrato concentrado e da farinha. Foram obtidos teores em torno de 54,08, 52,44 e 19,08g $100 \mathrm{~g}^{-1}$ para umidade; 2,16, 4,09 e 4,48g $100 \mathrm{~g}^{-1}$ para cinzas; 3,74, 2,77 e $5,73 \mathrm{~g} 100 \mathrm{~g}^{-1}$ para proteina bruta; $1,42,0,37$ e $1,82 \mathrm{~g} 100 \mathrm{~g}^{-1}$ para extrato etéreo; $12,56,3,33$ e 25,62 $100 \mathrm{~g}^{-1}$ para fibra alimentar; 19,46, 37,34 e 42,53g 100 $\mathrm{g}^{-1}$ para açúcares totais, além do valor calórico de 105,56, 165,14 e 216,09kcal $100 \mathrm{~g}^{-1}$, respectivamente, em fruto, extrato concentrado e farinha. $A$ quantificação por cromatografia líquida confirmou o conteúdo dos açúcares redutores (frutose, $6,15 \mathrm{~g} 100 \mathrm{~g}^{-1}$ e glicose, $6,57 \mathrm{~g}$ $\left.100 \mathrm{~g}^{-1}\right)$ superior ao teor de açucares não redutores no fruto (sacarose, 3,56g $100 \mathrm{~g}^{-1}$ ). A farinha é rica em açúcares e possui elevado teor de fibra alimentar, podendo ser utilizada como um ingrediente alternativo em produtos de panificação. Em termos sensoriais, o extrato concentrado obteve um indice de aceitabilidade de $82 \%$ entre os julgadores, apresentando bom potencial para elaboração de geleias.
\end{abstract}

Palavras-chave: açúcares, cromatografia líquida, qualidade, fibra alimentar.

\section{ABSTRACT}

Hovenia dulcis, whose popular name is Japanese grape, belongs to the family Rhamnaceae, native of China, Japan and Korea, is widely distributed in southern Brazil. Rich in sugar and with good acceptance for human consumption it can be consumed fresh or processed. There are no literature reports of its use in food products. The aim of this study was to determine the chemical composition of the Japanese grape fruit, concentrated extract and flour. The contents for moisture

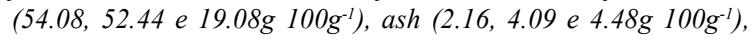
protein $\left(3.74,2.77\right.$ e $\left.5.73 \mathrm{~g} 100 \mathrm{~g}^{-1}\right)$, ethereal extract $(1.42$,

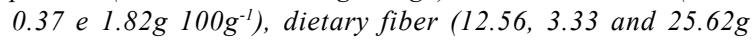

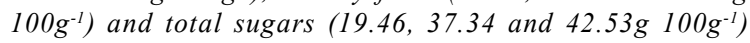
were obtained for the fruit, concentrated extract and flour, respectively. Quantification by liquid chromatography confirmed that the content of reducing sugars (fructose, $6.15 \mathrm{~g}$ $100 \mathrm{~g}^{-1}$ and glucose, $6.57 \mathrm{~g}_{\left.100 \mathrm{~g}^{-1}\right)}$ is higher than the non-

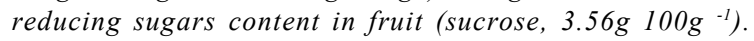
Calories resulted in values of $105.56,165.14$ and $216.09 \mathrm{kcal}$ $100 \mathrm{~g}^{-1}$ for fruit, concentrated extract and flour, respectively. The flour is rich in sugars and has a high content of dietary fiber being able to be used as an alternative ingredient in bakery products. Sensory analysis of the concentrated extract revealed an acceptability rate of $82 \%$ among the judges, showing good potential for jams' production.

Key words: sugars, liquid chromatography, quality, dietary fiber.

\section{INTRODUÇÃO}

O Brasil é um dos três maiores produtores mundiais de frutas, algo em torno de 43 milhões de toneladas por ano (IBRAF, 2007). A fruticultura nacional, no entanto, tem ainda grande potencial de expansão, pois há inúmeras frutas nativas e exóticas pouco exploradas economicamente (LAGO et al., 2006).

'Programa de Pós-graduação em Tecnologia de Alimentos, Universidade Federal do Paraná (UFPR), 81531-980, Curitiba, PR, Brasil. E-mail: ribani@ufpr.br.*Autor para correspondência.

"Departamento de Engenharia Química, UFPR, Curitiba, PR, Brasil. 
Dentre elas, a uva-do-japão (Hovenia dulcis Thunberg, Rhamnaceae) ou grape from the Japanese raisin tree (Japanese grape), cujo nome em japonês é kenponashi, é uma espécie florestal que pode crescer até $25 \mathrm{~m}$ de altura e ocorre naturalmente na China, Japão e Coréia, tendo sido introduzida no Nepal, na Índia, no Paraguai, na Argentina e na região Sul do Brasil. Por apresentar tolerância a geadas e multiplicidade de usos, esta espécie tornou-se importante para a região Sul, sendo recomendada para arborização de culturas, pastagens, cerca viva, uso em serraria e produção de energia (INOUE et al., 1978, CARVALHO, 1994; BUONO et al., 2008).

O fruto desta árvore é uma cápsula globosa seca, formada por três loculares, do tamanho de uma ervilha, contendo as sementes. O pedúnculo respectivo tem coloração castanha escura, é carnoso, suculento, saboroso e rico em sacarose, tendo a polpa aroma idêntico ao da pêra, sendo geralmente chamado "fruto". Também é utilizado pela fauna silvestre e para complementar a alimentação de suínos e aves (CARVALHO, 1994). Segundo LEE et al. (2002), apenas o fruto da Hovenia dulcis é utilizado como alimento e vários compostos foram isolados do extrato da uvado-japão, dentre eles flavonoides e polissacarídeos complexos.

Tendo em vista que não há na literatura relatos de seu aproveitamento em produtos na alimentação humana, existe a necessidade de melhor caracterização da uva-do-japão e sua utilização como ingrediente alimentício. Sendo assim, o presente trabalho teve por objetivo determinar a composição centesimal do fruto, do extrato concentrado e da farinha, além da quantificação da frutose, glicose e sacarose por cromatografia líquida no fruto da Hovenia dulcis.

\section{MATERIAL E MÉTODOS}

Matéria - prima

Os frutos maduros da uva-do-japão foram coletados em diferentes jardins da cidade de Curitiba/ PR no mês de junho de 2009. Foram desprezadas as sementes e os frutos que continham rachaduras, polpa mole ou partes escuras. Os frutos selecionados e higienizados foram desidratados em estufa com circulação de ar a $60^{\circ} \mathrm{C}$ por aproximadamente 36 horas, até peso constante. Em seguida, foram triturados em moinho (A11 BASIC - fabricante IKA) e acondicionados em embalagem de polietileno sob refrigeração até o momento das análises.

Preparo do extrato concentrado

Os sólidos dos frutos desidratados e triturados foram extraídos com água a $60^{\circ} \mathrm{C}$ na proporção de 1:1 (p/p) e filtrados em peneira de 20 mesh. O resíduo sólido foi separado para o preparo da farinha, e o extrato solúvel obtido foi concentrado através de aquecimento em tacho de aço inoxidável com capacidade para cinco litros, com agitação manual contínua até atingir $62^{\circ} \mathrm{Brix}$, medido em refratômetro. $\mathrm{O}$ extrato concentrado foi acondicionado em frascos de vidro e mantido sob refrigeração até o momento das análises.

Preparo da farinha

O resíduo sólido separado na filtração do preparo do extrato concentrado foi desidratado em estufa a $60^{\circ} \mathrm{C}$ com circulação de ar por aproximadamente 20 horas, até peso constante. Em seguida, o material seco foi triturado em moinho (A11 BASIC - fabricante IKA), obtendo-se a farinha, que foi acondicionada em embalagem de polietileno e mantida em temperatura ambiente até o momento das análises.

Composição centesimal

A composição centesimal do fruto da uvado-japão foi feita com base na matéria seca, sendo os resultados convertidos para matéria úmida; enquanto que, para o extrato concentrado e a farinha, todas as determinações foram feitas com base na matéria úmida.

$\mathrm{O}$ teor de umidade foi determinado pelo método da secagem em estufa $\left(105^{\circ} \mathrm{C} \pm 5^{\circ} \mathrm{C}\right)$, de acordo com metodologia da AOAC (2007), até a obtenção de peso constante. As cinzas foram obtidas a partir do princípio da incineração em mufla a $550^{\circ} \mathrm{C}$, até a obtenção de peso constante (AOAC, 2007). A determinação de proteína bruta foi realizada pelo método de Kjeldahl, no qual se avaliou o teor de nitrogênio orgânico total (AOAC, 2007). Para converter o resultado em proteína bruta, foi utilizado o fator 6,25 . O extrato etéreo ou lipídeos totais foram determinados pelo método de extração de Soxhlet, segundo a AOAC (2007). Os açúcares redutores e não redutores foram determinados pelo método de Lane-Eynon, utilizandose solução de Fehling (IAL, 2005). O teor de fibra alimentar total foi determinado pelo método enzimático - gravimétrico, segundo AOAC (2007). O valor calórico $\left(\mathrm{kcal} 100 \mathrm{~g}^{-1}\right)$ foi determinado aplicando os valores de conversão de ATWATER que considera $4 \mathrm{kcal} \mathrm{g}^{-1}$ para proteínas e açúcares totais e $9 \mathrm{kcal} \mathrm{g}^{-1}$ para lipídeos (ANDERSON, 1988).

Análise de açúcares por cromatografia

Para análise cromatográfica, os açúcares de

$50 \mathrm{~g}$ de amostra moída e homogeneizada dos frutos in natura maduros da uva-do-japão foram extraídos com $50 \mathrm{ml}$ de água a $60^{\circ} \mathrm{C}$ e, após filtração, obteve-se o extrato aquoso do fruto. Foi utilizado cromatógrafo a líquido da HP/AGILENT 1100, com detector de Índice de 
Refração a $40^{\circ} \mathrm{C}$. Para a separação dos açúcares, foi utilizada uma coluna Zorbax CARBOHYDRATE (150x4,6mm, tamanho das partículas: $5 \mathrm{~m}$ ) e fase móvel composta de acetonitrila:água $(80: 20, \mathrm{v} / \mathrm{v})$, a uma

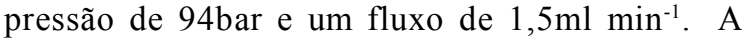
concentração de cada açúcar foi determinada por padronização externa frente às respectivas áreas nos tempos de retenção obtidos para os padrões de frutose $3,1 \mathrm{~min}$, glicose $3,4 \mathrm{~min}$ e sacarose $5,1 \mathrm{~min}$.

Análise sensorial

O extrato concentrado da uva-do-japão foi avaliado por 64 julgadores não selecionados, não treinados, de ambos os sexos (59\% feminino e $41 \%$ masculino) e de várias idades, através do teste de aceitação com escala hedônica de 9 pontos, variando de 1 (desgostei muitíssimo) a 9 (gostei muitíssimo) segundo metodologia IAL (2005). A amostra foi constituída por $15 \mathrm{~g}$ do produto em temperatura ambiente, servido em copo branco descartável, tendo biscoito água e sal como veículo.

\section{RESULTADOS E DISCUSSÃO}

Composição centesimal do fruto

Os dados referentes à composição centesimal da uva-do-japão analisada no presente trabalho e a relatada por outros autores estão apresentados na tabela 1 , sendo que se espera uma diferença nos resultados uma vez que as amostras são de diferentes estádios de maturação, variedade, época do ano ou mesmo procedência.
$\mathrm{O}$ teor de umidade $\left(54,08 \mathrm{~g}^{\left.100 \mathrm{~g}^{-1}\right)}\right.$ encontrado no fruto da uva-do-japão foi inferior ao teor de umidade $\left(60,86 \mathrm{~g}_{\left.100 \mathrm{~g}^{-1}\right)}\right.$ encontrado por ALMEIDA \& VALSECHI (1966), e inferior a outras

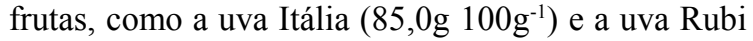

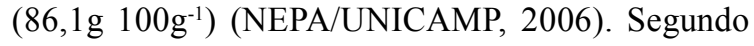
CECCHI (2003), altos teores de cinzas em alimentos, como os encontrados para Hovenia dulcis $\left(2,16 \mathrm{~g} \cdot 100 \mathrm{~g}^{-1}\right)$, indicam grandes quantidades de $\mathrm{K}, \mathrm{Na}, \mathrm{Ca}$ e $\mathrm{Mg}$. MOECKE et al. (2000), ao estudarem a composição química das cinzas dos frutos de uva-do-japão,

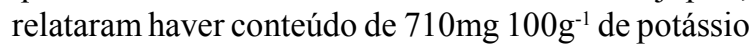
e $190 \mathrm{mg}^{100 \mathrm{~g}^{-1}} \mathrm{de}$ sódio nas amostras. Conforme tabela 1 , o teor de proteínas da amostra em estudo $(3,74 \mathrm{~g}$ $\left.100 \mathrm{~g}^{-1}\right)$ se aproxima ao relatado por ALMEIDA \& VALSECHI (1966) e MOECKE et al. (2000). Como o método de Kjeldahl para determinação de proteínas se baseia no teor de nitrogênio orgânico total, outros compostos nitrogenados, como as porfirinas, podem estar incluídos no teor de proteínas. O fruto da uva-dojapão apresentou baixo teor de lipídeos $\left(1,42 \mathrm{~g} 100 \mathrm{~g}^{-1}\right)$. De acordo com ROCHA et al. (2008), frutas e hortaliças possuem baixas quantidades de lipídeos enquanto as oleaginosas apresentam maiores teores deste componente.

Os açúcares totais encontrados na uva-dojapão $\left(19,46 \mathrm{~g} 100 \mathrm{~g}^{-1}\right)$ são superiores aos da uva Itália

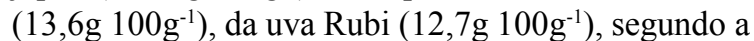
Tabela Brasileira de Composição de Alimentos (NEPA/ UNICAMP, 2006), e ao da cana de açúcar (12,5g $\left.100 \mathrm{~g}^{-1}\right)$, segundo CHEN \& CHOU (1993). O teor de açúcares redutores (glicose e frutose), determinados na uva-do-

Tabela 1 - Composição centesimal da uva-do-japão.

\begin{tabular}{|c|c|c|c|c|c|}
\hline \multirow{3}{*}{ Análises $(\mathrm{n} * *=3)$} & \multicolumn{5}{|c|}{ 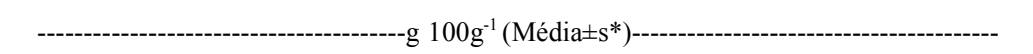 } \\
\hline & \multicolumn{2}{|c|}{ Presente Trabalho } & \multicolumn{2}{|c|}{ ALMEIDA \& VALSECHI (1966) } & \multirow{2}{*}{$\begin{array}{c}\text { MOECKE et al. (2000) } \\
\text { Base úmida }\end{array}$} \\
\hline & Base úmida & Base seca & Base úmida & Base seca & \\
\hline Umidade & $54,08 \pm 0,31$ & - & 60,86 & - & - \\
\hline Cinzas & $2,16 \pm 0,04$ & 4,71 & 0,85 & 2,17 & - \\
\hline Proteína bruta $(\mathrm{Nx} 6,25)$ & $3,74 \pm 0,35$ & 8,15 & 3,18 & 8,12 & 3,0 \\
\hline Lipídeos & $1,42 \pm 0,33$ & 3,08 & 0,39 & 0,99 & 1,6 \\
\hline Fibra bruta & - & - & 5,46 & 13,95 & - \\
\hline Fibra Alimentar & $12,56 \pm 0,10$ & 27,34 & _- & _- & - \\
\hline Açúcares redutores & $12,57 \pm 0,39$ & 27,38 & 14,27 & 36,46 & - \\
\hline Açúcares não redutores & $6,89 \pm 0,54$ & 15,00 & 14,06 & 35,92 & _ \\
\hline Açúcares totais & 19,46 & 42,38 & 28,33 & 72,38 & - \\
\hline Carboidratos calculados por diferença & - & _- & - & _- & 47,6 \\
\hline 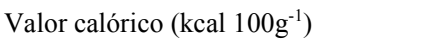 & 105,56 & 229,87 & 129,55 & 330,99 & 216,8 \\
\hline
\end{tabular}

$*_{\mathrm{S}}=$ Desvio Padrão; $* * \mathrm{n}=$ número de repetições. 


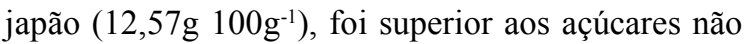

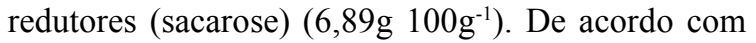
BALBACH \& BOARIM (1992), a maioria das frutas apresentam teor de açúcar não redutor menor que açúcar redutor. No que se refere ao conteúdo de fibra alimentar $\left(12,56 \mathrm{~g} 100 \mathrm{~g}^{-1}\right)$, a uva-do-japão apresentou teores superiores a outras variedades de frutas exóticas, como tamarindo $\left(6,4 \mathrm{~g} 100 \mathrm{~g}^{-1}\right)$ e jambo $\left(5,1 \mathrm{~g} 100 \mathrm{~g}^{-1}\right)$ (NEPA/UNICAMP, 2006). A determinação de fibra alimentar pelo método enzimático-gravimétrico, utilizado neste trabalho, quantifica as frações de fibras solúveis e insolúveis, resultando em valores mais representativos do verdadeiro teor de fibras e superiores aos apresentados por ALMEIDA \& VALSECHI (1966), que determinou o teor de fibra bruta, em desuso para alimentação humana. Uma vez que o fruto apresentou um teor de fibra alimentar superior a $3 \mathrm{~g} 100 \mathrm{~g}^{-1}$, pode ser classificado como "fonte de fibras", de acordo com o estabelecido pela legislação brasileira (BRASIL, 1998). O alto conteúdo de fibra alimentar da amostra estudada também contribuiu para diminuição

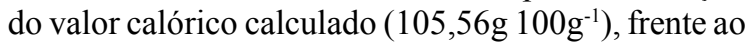
apresentado pelos demais autores.

Análise de açúcares por cromatografia do fruto

Os teores determinados através da análise cromatográfica para açúcares redutores fo-ram de $6,15 \mathrm{~g}$ $100 \mathrm{~g}^{-1}$ para a frutose e $6,57 \mathrm{~g} 100 \mathrm{~g}^{-1}$ para a glicose, conforme apresentados na tabela 2 . O teor de açúcar não redutor foi de $3,56 \mathrm{~g} 100 \mathrm{~g}^{-1} \mathrm{em}$ sacarose, assim, os

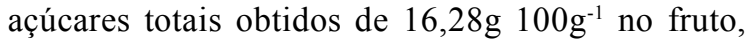
determinados por cromatografia, são próximos aos obtidos pelo método titrimétrico de oxi-redução por Lane-Eynon de 19,46g $100 \mathrm{~g}^{-1}$ (Tabela 1). A presença de açúcares redutores (frutose e glicose) é um fator de qualidade na aceitação do fruto in natura ou processado (LAGO et al., 2006), sendo a frutose cerca de $1,3-1,8$ vezes mais doce que a sacarose e 2,4 vezes mais doce que a glicose, além de ser o mais solúvel dos açúcares usualmente encontrados nos alimentos (BOBBIO \& BOBBIO, 2001; BURKET, 2003). De acordo com BURKET (2003), o uso da frutose na alimentação humana, em comparação à glicose e à sacarose, resulta em efeito glicêmico reduzido, assim, o fruto da uva-dojapão pode ser empregado com vantagem em alimentos para fins especiais.
Composição centesimal do extrato concentrado e da farinha

Os dados referentes à composição centesimal do extrato concentrado e da farinha de uvado-japão analisados neste trabalho estão apresentados na tabela 3. No extrato concentrado, os resultados

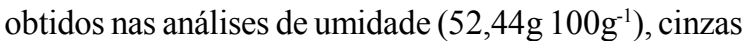
$\left(4,09 \mathrm{~g}_{100 \mathrm{~g}^{-1}}\right)$, proteínas $\left(2,77 \mathrm{~g} 100 \mathrm{~g}^{-1}\right)$ e lipídeos $(0,37 \mathrm{~g}$ $\left.100 \mathrm{~g}^{-1}\right)$ foram superiores aos encontrados para a geleia convencional de uva, que apresentou teores de umidade, cinzas, proteínas e lipídeos em torno de $34,99 \mathrm{~g}$

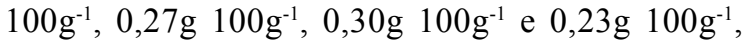
respectivamente, segundo a tabela de Composição de Alimentos - USP (TBCA/USP, 1998). O extrato concentrado apresentou teores de açúcares totais

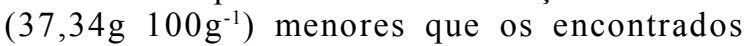
normalmente em geleias e doces em pasta de frutas convencionais, como geleia de pêssego $(67,35 \%)$, geleia de amora $(64,62 \%)$ e doce de banana $(68,11 \%)$, citados por ROCHA et al. (2003), NACHTIGALL et al. (2004), e BELTRÃO FILHO \& SILVA(2006), respectivamente. O teor de fibra alimentar presente no extrato concentrado $\left(3,33 \mathrm{~g} 100 \mathrm{~g}^{-1}\right)$ permite a utilização deste em dieta rica em fibras (BRASIL, 1998), sendo superior ao relatado para outros doces, como o de banana integral $(0,629 \%)$, citado por SILVA \& RAMOS (2009). O valor calórico obtido para o extrato concentrado $\left(165,14 \mathrm{kcal}^{\left.100 \mathrm{~g}^{-1}\right)}\right.$ foi inferior ao encontrado em geleia convencional de

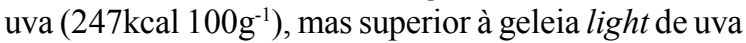
$\left(105 \mathrm{kcal}^{100 \mathrm{~g}^{-1}}\right)$, de acordo com a tabela de Composição de Alimentos - USP (TBCA/USP, 1998).

A composição da farinha de uva-do-japão apresentou teor de umidade $\left(19,08 \mathrm{~g} 100 \mathrm{~g}^{-1}\right)$ e cinzas

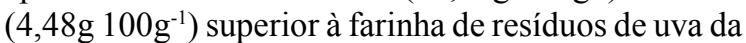
variedade Niágara (Vitis Labrusca) (umidade: $2,67 \mathrm{~g}$ $100 \mathrm{~g}^{-1}$ ) e (cinzas: $2,67 \mathrm{~g}^{100 \mathrm{~g}^{-1}}$ ), estudada por OLIVEIRA et al. (2009). Por outro lado, o teor de lipídeos $(1,82 \mathrm{~g}$

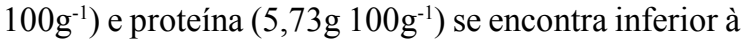
farinha de resíduos de uva da variedade Niágara

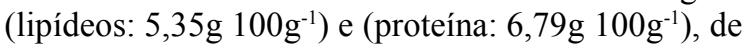
acordo com OLIVEIRA et al. (2009). A farinha apresentou teor de fibra alimentar $\left(25,62{\left.\mathrm{~g} 100 \mathrm{~g}^{-1}\right)}^{-1}\right.$ superior quando comparada com a farinha de trigo $(2,3 \mathrm{~g}$ $\left.100 \mathrm{~g}^{-1}\right)(\mathrm{NEPA} / \mathrm{UNICAMP}, 2006)$ e a farinha de banana verde $\left(17,98 \mathrm{~g} 100 \mathrm{~g}^{-1}\right)$ estudada por MIRANDA et al. (2008), indicando que o produto também pode ser

Tabela 2 - Resultados de açúcares por cromatografia líquida.

\begin{tabular}{|c|c|c|c|c|}
\hline \multicolumn{5}{|c|}{ g $100 \mathrm{~g}^{-1}\left(\right.$ Média $\left.\pm \mathrm{s}^{*}\right)$} \\
\hline \multirow{2}{*}{ Amostra $\left(n^{* *}=3\right)$} & ---------Açúce & tores---------- & Açúcares não redutores & Açúcares totais \\
\hline & Glicose & Frutose & Sacarose & \\
\hline Uva-do-japão & $6,57 \pm 0,32$ & $6,15 \pm 0,28$ & $3,65 \pm 0,21$ & 16,28 \\
\hline
\end{tabular}

*s=Desvio Padrão; **n= número de repetições. 
Tabela 3 - Composição centesimal do extrato concentrado e da farinha da uva-do-japão.

\begin{tabular}{|c|c|c|c|c|}
\hline & \multicolumn{2}{|c|}{ Extrato concentrado } & \multicolumn{2}{|c|}{ Farinha } \\
\hline $\begin{array}{l}\text { Teores }\left(\mathrm{g} 100 \mathrm{~g}^{-1}\right) \\
\text { Média } \pm \mathrm{s}^{*} ; \mathrm{n}^{* *}=3\end{array}$ & Base úmida & Base seca & Base úmida & Base seca \\
\hline Umidade & $52,44 \pm 0,94$ & - & $19,08 \pm 1,60$ & - \\
\hline Cinzas & $4,09 \pm 0,24$ & 8,55 & $4,48 \pm 0,37$ & 5,53 \\
\hline Proteína bruta $(\mathrm{Nx} 6,25)$ & $2,77 \pm 0,04$ & 5,79 & $5,73 \pm 0,38$ & 7,08 \\
\hline Lipídeos & $0,37 \pm 0,01$ & 0,52 & $1,82 \pm 0,19$ & 2,56 \\
\hline Fibra alimentar & $3,33 \pm 0,03$ & 6,97 & $25,62 \pm 0,06$ & 31,66 \\
\hline Açúcares redutores & $24,24 \pm 0,30$ & 27,40 & $26,17 \pm 0,46$ & 32,34 \\
\hline Açúcares não redutores & $13,10 \pm 0,24$ & 50,70 & $16,36 \pm 0,97$ & 20,22 \\
\hline Açúcares totais & 37,34 & 78,10 & 42,53 & 52,56 \\
\hline Valor calórico $\left(\mathrm{kcal} 100 \mathrm{~g}^{-1}\right)$ & 165,14 & 340,25 & 216,09 & 261,62 \\
\hline
\end{tabular}

$*_{\mathrm{s}}=$ Desvio Padrão; $* * \mathrm{n}=$ número de repetições.

incluído na dieta como alimento "fonte de fibras" (BRASIL, 1998). O teor de açúcares redutores $(26,17 \mathrm{~g}$ $\left.100 \mathrm{~g}^{-1}\right)$, comparativamente superior aos açúcares não

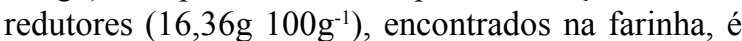
um fator positivo na sua utilização em produtos alimentícios dietéticos, podendo também ser utilizada em farinhas mistas para o preparo de produtos de panificação. Também é uma alternativa para reduzir o desperdício de subprodutos da indústria alimentícia. O valor calórico $\left(216,09 \mathrm{~g}_{100 \mathrm{~g}^{-1}}\right)$ da farinha de uva-dojapão foi inferior ao da farinha de banana verde $(373,00 \mathrm{~g}$ $100 \mathrm{~g}^{-1}$ ), estudado por BORGES et al.(2009).
Análise sensorial do extrato concentrado

O extrato concentrado de uva-do-japão apresentou coloração escura, sabor doce e consistência homogênea característica de doce cremoso. O produto apresentou boa aceitação, com média de 7,36 correspondendo ao índice de aceitabilidade de $82 \%$. Segundo DUTCOSKI (2007), um produto é bem aceito quando tem no mínimo $70 \%$ no índice de aceitabilidade. Com relação ao número de julgadores, $92 \%$ atribuíram notas superiores a 5 e apenas $6 \%$ notas inferiores a 5 (Figura 1). Além disso, o extrato concentrado foi considerado muito doce por $5 \%$ dos julgadores e $8 \%$

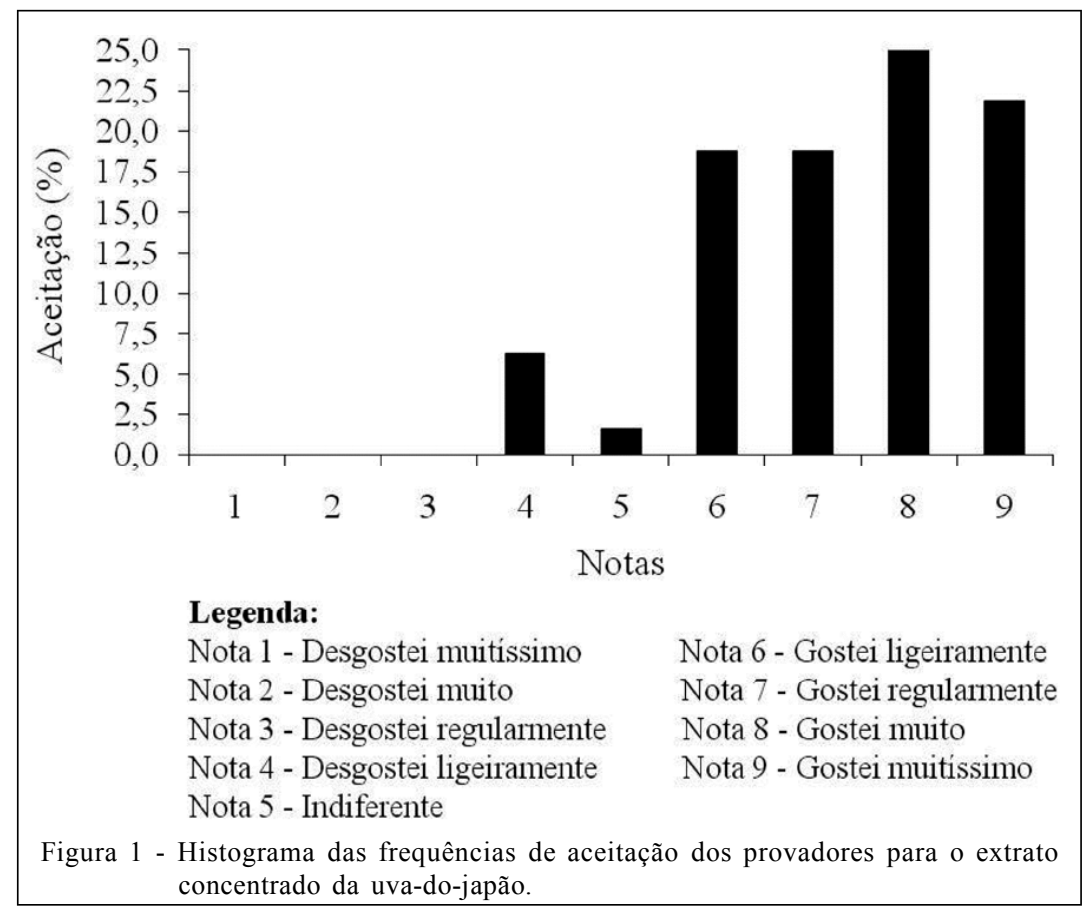

Ciência Rural, v.40, n.11, nov, 2010. 
associaram o sabor a outros produtos, como doce de banana, doce de uva e açúcar mascavo.

\section{CONCLUSÃO}

O teor de açúcares redutores representou a maior parcela dos açúcares totais da uva-do-japão, com proporções semelhantes entre glicose e frutose. Os elevados teores de fibra alimentar e açúcares encontrados na uva-do-japão e seus derivados (extrato concentrado e farinha) indicam que podem ser incluídos na dieta como alimento fonte de fibras ou na utilização para enriquecimento nutricional de produtos. A análise sensorial indicou um índice de aceitabilidade de $82 \%$ para o extrato concentrado obtido da uva-do-japão.

\section{REFERÊNCIAS}

ALMEIDA, J.R. de; VALSECHI, O. Guia de composição de frutas. Piracicaba: ESALQ, Instituto Zimotécnico, 1966. 250p. (Boletim Técnico, 21).

ANDERSON, L.A. et al. Nutrição. Rio de Janeiro: Guanabara, 1988. Cap.10, p.179-187.

AOAC. (ASSOCIATION OF OFFICIAL ANALYTICAL CHEMISTS). Official methods of analysis. 18.ed. Washington: AOAC, 2007. 3000p.

BALBACH, A.; BOARIM, D.S.F. As frutas da medicina natural. 2.ed. Itaquaquecetuba: Vida Plena, 1992. 316p.

BELTRÃO FILHO, E.M.; SILVA, M. do L.P. da. Processamento de doce em massa de banana (Musa sp) - cultivar nanicão. In: JORNADA NACIONAL DA AGROINDÚSTRIA; 2006, Bananeiras, Brasil. Proceedings... Bananeiras: Seminagro, 2006. Acesso em: 12 nov. 2009. Online. Disponível em: ht tp://www.seminagro.com.br/VII/CMS/UpFiles/ 23122009061259_01cta.pdf.

BOBBIO, P.A.; BOBBIO, F.O. Química do processamento de alimentos. 3.ed. São Paulo: Varela, 2001. 144p.

BORGES, A.M. et al. Caracterização da farinha de banana verde. Ciência e Tecnologia de Alimentos, v.29, n.2, p.333$339,2009$.

BRASIL. Portaria n.27 SVS/MS, de 13 de janeiro de 1998. A Secretaria de Vigilância Sanitária do MS aprova o Regulamento Técnico referente à Informação Nutricional complementar. Diário Oficial da União, 199816 jan (11-E):1; Seção 1.

BUONO, R.A. et al. Anatomy, ultrastructure and chemical composition of food bodies of Hovenia dulcis (Rhamnaceae). Annals of Botany, v.101, p.1341-1348, 2008. Disponível em: <www.aob.oxfordjournals.org $>$. Acesso em: 20 nov. 2009. doi: $10.1093 / \mathrm{aob} / \mathrm{mcn} 052$.

BURKET, C.A.V. Separação de glicose, frutose, oligossacarídeos e dextranas utilizando zeólitas. 2003. 177f. Tese (Doutorado em Engenharia de Alimentos) - Curso de Pós-graduação em Engenharia de Alimentos, Universidade Estadual de Campinas, SP.
CARVALHO, P.E.R. Ecologia, silvicultura e usos da uvado-japão (Hovenia dulcis Thunberg). Colombo: Embrapa CNPFloresta, 1994. 24p. (Boletim Técnico, 23).

CECCHI, H.M. Fundamentos teóricos e práticos em análise de alimentos. 2.ed. Campinas: Unicamp, 2003. 207 p.

CHEN, J.C.P.; CHOU, C. Cane sugar handbook. A manual for cane sugar manufacturers and their chemists. 12.ed. New York John Wiley \& Sons, 1993. 1090p.

DUTCOSKI, S.D. Análise sensorial de alimentos. Curitiba: Champagnat, 2007. 123p.

I.A.L. (INSTITUTO ADOLFO LUTZ). Normas analíticas do Instituto Adolfo Lutz: métodos químicos e físicos para análises de alimentos. 3.ed. São Paulo, 2005. 1v.

IBRAF. (INSTITUTO BRASILEIRO DE FRUTAS). Missão brasileira ao Norte da África. Frutas e derivados. 6.ed. Junho 2007. Acesso em: 25 nov. 2009. Online. Disponível em: http://www.ibraf.org.br/x_files/revista06.pdf.

INOUE, O. et al. Carbohydrate structures of three new saponins from the Root Bark of Hovenia dulcis (Rhamnaceae). Journal of the Chemical Society, Perkin Trans. v.1, p.1289-1293, 1978.

LAGO, E.S. et al. Produção de geléia de jambolão (Syzygium cumini Lamarck): processamento, parâmetros físico - químicos e avaliação sensorial. Ciência e Tecnologia de Alimentos, v.26, n.4, p.847-852, 2006.

LEE, H.Y. et al. Hovenodulinol, an active compound extracted from hovenia dulcis thunb, a process for preparing the same, and an alcohol decomposing agent or an agent for allevating lingering intoxication containing the same, wo/2002/024678, 28 mar. 2002. Acesso em: 15 out. 2009. Online. Disponível em: <http:// www.wipo.int/pctdb/en/wo.jsp?wo=2002024678> .

MIRANDA , L.M.O. et al. Composição de pão de banana enriquecido com farinha de banana verde, aveia e farelo de aveia. In: CONGRESSO BRASILEIRO DE CIÊNCIA E TECNOLOGIA DE ALIMENTOS, 21.; SEMINÁRIO LATINO AMERICANO E DO CARIBE DE CIÊNCIA E TECNOLOGIA DE ALIMENTOS, 15., 2008, Belo Horizonte. Ciência e inovação para o desenvolvimento sustentável. Belo Horizonte: SBCTA, 2008. 1 CD-ROM.

MOECKE, E.H.S. et al. Composição química e estudo das estruturas histológicas do pedúnculo da Hovenia dulcis. In: CONGRESSO BRASILEIRO DE CIÊNCIAS E TECNOLOGIA DE ALIMENTOS, 17., 2000, Fortaleza. Alimentos para o terceiro milênio. Fortaleza: SBCTA, 2000. Impresso.

NACHTIGALL, A.M. et al. Geléias light de amora-preta. Boletim do Centro de Pesquisa e Processamento de Alimentos, v.22, n.2, p.337-354, 2004.

NEPA. (NÚCLEO DE ESTUDOS E PESQUISAS EM ALIMENTAÇÃO). Tabela brasileira de composição de alimentos - TACO. Versão II. 2.ed. Campinas: UNICAMP, 2006. 113p. Acesso em: 23 out. 2009. Online. Disponível em: <www.unicamp.br/nepa/taco/tabela.php?ativo=tabela $>$. 
OLIVEIRA, L.T. et al. Caracterização físico-química da farinha de semente e casca de uva. In: SEMANA DE CIÊNCIA E TECNOLOGIA DO IFMG, 2.; JORNADA CIENTIFICA, 2., 2009, Bambuí, Brasil. Proceedings... Bambuí: Instituto Federal de Minas Gerais, 2009. Acesso em: 4 jun. 2010. Online. Disponível em: http://www.cefetbambui.edu.br/sct/trabalhos/ Produ\%C3\%A7\%C3\%A30\%20Aliment\%C3\%ADcia/94PT.pdf.

ROCHA, S.A. et al. Fibras e lipídios em alimentos vegetais oriundos do cultivo orgânico e convencional. Revista SimbioLogias, v.1, n.2, p.135-143, 2008.

ROCHA, F.G. et al. Características de geléias light de pêssego elaboradas com diferentes edulcorantes. In: SIMPÓSIO EM CIÊNCIA DE ALIMENTOS - ALIMENTOS E
SAÚDE, 2., 2003, Florianópolis. Anais... Florianópolis: UFSC, 2003. p.979-1107.

SHELL BRASIL. A usina açucareira e sua lubrificação. Rio de Janeiro: Shell Brasil, 1959. 99p.

SILVA, M.B. de L. da; RAMOS A.M. Composição química, textura e aceitação sensorial de doces em massa elaborados com polpa de banana e banana integral. Revista Ceres, v.56, n.5, p.551-554, 2009.

UNIVERSIDADE DE SÃO PAULO - USP. Departamento de Alimentos e Nutrição Experimental/BRASILFOODS, Faculdade de Ciências Farmacêuticas. Tabela Brasileira de Composição de Alimentos - TBCA/USP. Versão 4.1. São Paulo, 1998. Acesso em 24 maio, 2010. Online. Disponível em: <http:// www.fcf.usp.br/tabela.>. 